\title{
A Descriptive Study towards Green Computing Practice Application for Data Centers in IT Based Industries
}

\author{
Bokolo Anthony Jnr. ${ }^{1, *}$, Mazlina Abdul Majid ${ }^{2}$, and Awanis Romli ${ }^{1}$ \\ ${ }^{1}$ Faculty of Computer Systems and Software Engineering, Universiti Malaysia Pahang, 26300 Gambang, Pahang, Malaysia
}

\begin{abstract}
The progressive upsurge in demand for processing and computing power has led to a subsequent upsurge in data center carbon emissions, cost incurred, unethical waste management, depletion of natural resources and high energy utilization. This raises the issue of the sustainability attainment in data centers of Information Technology (IT) based industries. Green computing practice can be applied to facilitate sustainability attainment as IT based industries utilizes data centers to provide services to staffs, practitioners and end users. But it is a known fact that enterprise servers utilize huge quantity of energy and incur other expenditures in cooling operations and it is difficult to address the needs of accuracy and efficiency in data centers while yet encouraging a greener application practice alongside cost reduction. Thus this research study focus on the practice application of Green computing in data centers which houses servers and as such presents the Green computing life cycle strategies and best practices to be practiced for better management in data centers in IT based industries. Data was collected through questionnaire from 133 respondents in industries that currently operate their in-house data centers. The analysed data was used to verify the Green computing life cycle strategies presented in this study. Findings from the data shows that each of the life cycles strategies is significant in assisting IT based industries apply Green computing practices in their data centers. This study would be of interest to knowledge and data management practitioners as well as environmental manager and academicians in deploying Green data centers in their organizations.
\end{abstract}

\section{Introduction}

Over the years the increasing need for computer related resources has resulted to a major growth in the figures of data center servers deployed along with an increase in the energy consumed by these servers. Data centers provides support to the present day digital economy based on the prevalent application and usage of cloud based services, but since data centers utilizes a substantial amount of power and also releases Carbon dioxide $(\mathrm{CO} 2)$ emission to the atmosphere [1], hence there is need for strategies, technics and technologies that can reduce $\mathrm{CO} 2$ emission from data center.

Green computing is one of these technologies that can help lessen $\mathrm{CO}_{2}$ emissions in data centers. Green computing aims to deploy and utilize technologies for a cleaner and Greener planet. Green computing is mainly the study and practice of utilizing computing resources proficiently [2]. It is a paradigm towards practicing costeffective and environment friendly use of energy.

Green computing can also be referred to as optimal utilization of Information Technology (IT) for governing the sustainability attainment of an organization. It involves activities that emphases on tactical deployment of IT to vigorously and ethically align organizations aims and objectives with environmental protection in mind during the complete industrial operations.
According to Uddin et al. [3] Green computing entails applications of ecological friendly IT based initiatives focused on organizational objectives. Hence Green computing practices can be applied in IT based industries data centers towards $\mathrm{CO}_{2}$ emissions reduction, cost incurred lessening, proper ethical waste management, depletion of natural resources lessening and high energy utilization decrease.

Data center energy consumption is anticipated to increase IT based industries costs and $\mathrm{CO}_{2}$ emissions. Hence Green computing practice application in data centers can help lessen these negative effects [4]. In continents such as Europe, the energy consumption of enterprise data centers for cooling and powering server equipment institutes large proportion electricity. Hence organizations such as IT based industries have called on policy makers to resolve data center electricity efficiency in order to certify that the linked impacts, such as societal, economic and environmental issues are mitigated [5].

In IT based industries data centers signify the buildings, rooms and facilities which encompass enterprise servers, networks communication infrastructures, cooling facilities and powering equipment that supports data providing services which may include data handling for intranet, internet, web hosting, IT and telecommunication cables, routers, hubs

*Corresponding author: bkanjr@gmail.com 
and switches [6]. Green computing in IT based industry data center involves the deployment of energy efficient IT such as electrical, lighting, computer systems and mechanical equipment with negligible environmental impact on the environment [7-9].

Therefore this research aims to conduct a descriptive study of how IT based industries can apply Green computing practices in their data centers in regards to cost saving decrease, energy efficiency, eco-friendly waste management, natural resource conservation and $\mathrm{CO}_{2}$ emission reduction towards sustainability attainment. To achieve the aims of this study it is imperative to identify the Green computing life cycle strategies to be applied for Greening data centers in IT based industries

But in order to identify the life cycle strategies to be applied in Greening data centers towards the application of best practices for cost saving decrease, energy efficiency, eco-friendly waste management, natural resource conservation and $\mathrm{CO}_{2}$ emission reduction, this research presents the life cycle strategies that are drawn from secondary data. The life cycle strategies are confirmed from primary data (questionnaire) collected from more than 133 respondents in IT based industries. More specifically the benefits of this study would have positive implications for IT based industries data center system practitioners and staffs by providing best practice towards the reductions of energy consumption and $\mathrm{CO}_{2}$ emissions.

The remainder of this article is structured as follows. The next section is the literature review. Then the research methodology is provided. Next, the results and findings from the questionnaire data collection are outlined. We then proceed to the discussion section, after which the research and practical implications are revealed. The article is concludes with conclusion, limitation and future work section.

\section{Literature review}

A few studies has be published that contributes to support Greening data centers in organizations, among this studies, 5 studies related to data centers Greening are reviewed in this section because they individually contributed to the presentation of Green computing life cycle strategies. Among the 5 studies that contributed to Greening data centers in organizations Karanasios et al. [1] carried out an exploratory case study by identifying the antecedents towards the adoption of techniques, technologies and best practices for Greening data centres. The authors developed a conceptual framework to explain the circumstances that might impact the implementation of the best practices in data centres Greening.

Molla and Cooper [9] investigated the motivation, ability drivers and expectancy for Greening data centres. The researchers resolved the issue relating to the institutional, motivation ability and expectancy concepts based on survey data collected from 96 data centres. Findings form their research shows that effort expectancy, ability and performance are the main drivers that influence practices and technologies implementation towards energy efficiency improvement in data centres.

Pawlish and Varde [6] proposed a decision support system based on decision trees and case based reasoning that collects existing campus data in order to facilitate decision-making for enhances data centers management for Greening campus data centers. Uddin et al. [3] utilized Green IT a developed framework for achieving energy efficient of data centers alongside the application of virtualization technique. The authors deployed Green IT to securely and seamlessly divide data center modules into different resource pools depending on different metrics such as energy utilization ratio, workloads consumption ratio, $\mathrm{CO} 2$ emission etc. The developed framework is grounded on cloud computing and virtualization to reduce the energy utilization ratio of deployed servers.

OGCIS [10] summarized a list of guidelines for implementing Green data center practices. The author utilized Green IT to lessen energy consumption and $\mathrm{CO}_{2}$ emission of data centres in government organizations. The report presented by the author can be used as a quick reference for Greening data centers environment. Also the practice outlines sets of endorsed practices applicable for attaining energy efficiency and minimising environmental impacts in data centre. The practices are characterized based on 4 lifecycle phases which comprises of design, procurement, operations and disposal.

Findings from the reviewed literatures shows that data centre Greening has been a issues to be addressed by industries such as IT based industries, although researchers such as Pichetpongsa and Campeanu [16] believes that the implementing of Green practices can help reduce the negative effects caused by IT usage in IT based industries.

Each of the review papers aims to contribute to address climatic changes and environmental problems none of the reviewed studies simultaneously addressed sustainability issues in data center in relation to energy efficiency, cost saving, natural resource preservation, waste management, and $\mathrm{CO}_{2}$ emissions. The reviewed studies are mainly concerned about energy efficiency, $\mathrm{CO}_{2}$ emission and waste management. Hence lifecycle strategies and metrics related cost saving and natural resource preservation was not fully addressed.

\section{Research methodology}

This descriptive study reports findings for data collected to verify life cycle strategies for applying Green computing practices in IT based industries data centers. The qualitative data for this study is collected from 133 respondents from IT based industries in Malaysia. The survey instrument was prepared by based on the descriptive nature of the study and following Hair et al. [11] procedures on data collection instrument development. Figure 1 shows the research methods adopted in this study, each of the phase shown in Figure 1 are carried out throughout this research paper. 


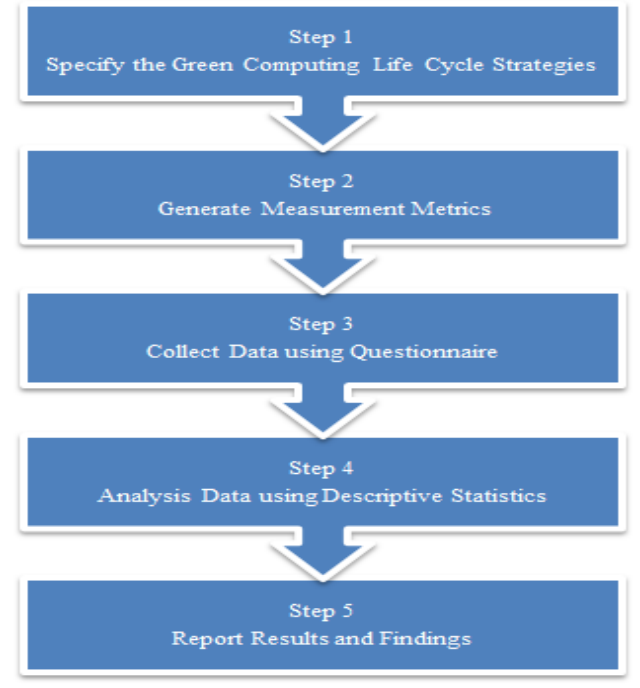

Fig. 1. Research process.

Figure 1 displays the research methods followed in this study. Each of the steps is further explored in sub sections of section 3 .

\subsection{Green computing life cycle strategies}

This section provides a theoretical and practical description of the process lifecycles strategies to be applied in practicing Green computing in IT based industries data centers. In this regards the lifecycle strategies are presented below;

\subsubsection{Green design}

Green design aims to analyse, create and synthesize ecological friendly products with outstanding efficiency. IT based industries usually disregarded environmental effects during design and as such hazardous wastes were discarded without the ecological issues being considered [12]. Therefore Green design in IT based industries data centers should consider energy proficient and deployment of ecologically sound servers, cooling equipment and computer components such as Light Emitting Diode (LED) monitor, etc. [13, 14].

\subsubsection{Green production}

This phase in IT based industries data centers involves taken steps toward applying Greener prospect by changing their data centers operations to more competent activities and also increasing the reutilizing and reusability rate of the existing infrastructures deployed in the data center [12]. As suggested by Pichetpongsa and Campeanu [13] in Green production every procedure involved in running the data center electronic components, computers and other related subsystems should indicate a low or no effect on the natural environment. This statement was also supported by Saha [14] who mentioned that in Green production electronic equipment which has negligible impact or no effect on the environment should only be installed.

\subsubsection{Green procurement}

In Green procurement IT based industries can also apply environmental purchasing practice that involves reduction, recycling and reuse of IT infrastructures in purchasing operations [14]. Moreover Green procurement promotes ecologically considerations and promotes the economically viability of the organization towards selecting and acquiring services and products that reduces environmental pollution [13]. Other Green procurement activities may include the practice of considering the Green track record of IT services and software vendors toward environmental protection [15].

\subsubsection{Green operations}

This strategy aims to save energy which leads to less emission of $\mathrm{CO} 2$ to the atmosphere when data centers servers are being deployment or implemented to facilitate IT based industries end users, staffs, practitioners and management. Hence, data center administrator should be aware of how Green operation can be applied towards to reducing energy consumption of data centers [12]. Green operation practices also aims to enhance power performance of IT based industries assets towards decreasing energy utilization of cooling and powering enterprise data centers assets, optimizing energy performance of data centers, reducing data centers induced $\mathrm{CO}_{2}$ emissions [17], practicing low carbon emitting corporate practices and lastly assessing the organizations total environmental footprint [15].

\subsubsection{Green disposal}

Green disposal provides IT based industries data centers with a flexible and audit policy solution for gathering; re-processing and recycling of end-of-life redundant IT associated equipment [18]. Hence in Green disposal IT base industries can plan to refurbish and reuse old data centers components, while other unwanted electronics components can be prepared for recycling operations [13]. Also OGCIS [10]; Molla [15] recommended that the reuse (extend life) or disposal of obsolete data centers equipment and IT related facilities should be dismantled or refurbished for reuse, while discarding of out-dated infrastructures should adhere to relevant ecological legislations guidelines such as waste disposal ordinance for end of equipment life dumping policy or they can utilize information systems to track the life-cycle of enterprise data center assets and ascertain the cost-benefit of different discarding methods [12].

Based on the identified and discussed life cycle strategies a research model is developed as seen in Figure 2 to be verified by the questionnaire data. The research model is verified to ascertain if each of the strategies are important and should be applied by IT based industries data centers in regards to energy efficiency, cost saving, natural resource preservation, waste management, and $\mathrm{CO} 2$ emissions. 


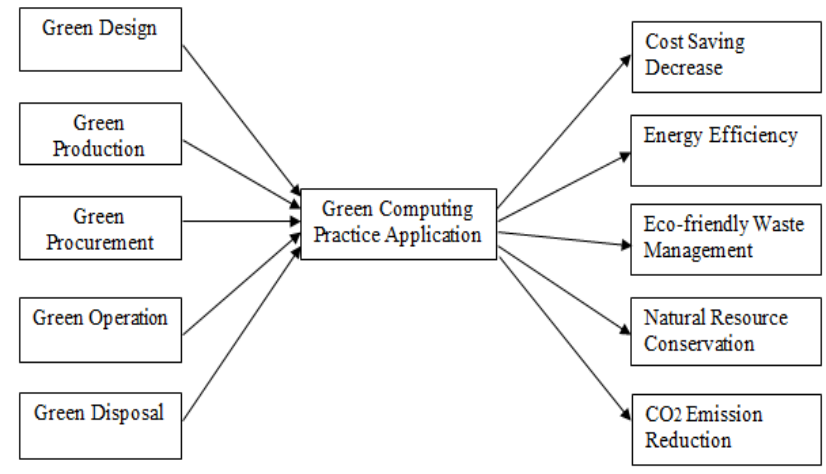

Fig. 2. Research model.

Figure 2 shows the research model developed based on the life cycle strategies that comprises of Green design, Green production, Green procurement, Green operation and Green disposal which influences Green computing practice application in IT based industries data centers towards cost saving decrease, energy efficiency, eco-friendly waste management, natural resource conservation and lastly $\mathrm{CO}_{2}$ emission reduction.

\subsection{Measurement metrics generation}

To measure the life cycle strategies presented in section 3.1 and Figure 2, metrics are derived from the literatures to assess each life cycle strategy, hence each of the metrics are shown in Table 1 to measures the degree to which each life cycle strategy relates to the application of Green computing practices in data centers.

Table 1. Operationalization of life cycle strategies and metrics

\begin{tabular}{|c|c|c|}
\hline $\begin{array}{l}\text { Life Cycle } \\
\text { Strategies }\end{array}$ & Code & Metrics \\
\hline \multirow[t]{6}{*}{$\begin{array}{l}\text { Green } \\
\text { Design }\end{array}$} & GDN1 & $\begin{array}{l}\text { Concerned about the energy consumption of } \\
\text { cooling and lighting in our data center. }\end{array}$ \\
\hline & GDN2 & $\begin{array}{l}\text { Concerned about the efficiency of powering } \\
\text { our IT infrastructure. }\end{array}$ \\
\hline & GDN3 & $\begin{array}{l}\text { Considers environmental factors in the } \\
\text { design of lighting, power delivery, cooling } \\
\text { systems and servers, storage and network. }\end{array}$ \\
\hline & GDN4 & $\begin{array}{l}\text { Relocate enterprise data center near clean } \\
\text { sources of energy/renewable energy. }\end{array}$ \\
\hline & GDN5 & $\begin{array}{l}\text { Use electricity supplied by Green energy } \\
\text { providers in our data center. }\end{array}$ \\
\hline & GDN6 & Enforces power management. \\
\hline \multirow[t]{8}{*}{$\begin{array}{l}\text { Green } \\
\text { Production }\end{array}$} & GPN1 & $\begin{array}{l}\text { Install software to make production more } \\
\text { environmentally friendly in our data center. }\end{array}$ \\
\hline & GPN2 & Retire energy inefficient systems \\
\hline & GPN3 & $\begin{array}{l}\text { Analyses IT's energy bill separately from } \\
\text { overall corporate bill in our data center. }\end{array}$ \\
\hline & GPN4 & $\begin{array}{l}\text { Engaging the service of a professional } \\
\text { service provider to maintain our data center. }\end{array}$ \\
\hline & GPN5 & Install more energy efficient lightings. \\
\hline & GPN6 & Upgrades to efficient transformers and UPS. \\
\hline & GPN7 & $\begin{array}{l}\text { Auditing the power efficiency for lesser } \\
\text { power consumption in our data center. }\end{array}$ \\
\hline & GPN8 & $\begin{array}{l}\text { Eliminates and di-commission unused } \\
\text { services and systems in our data center. }\end{array}$ \\
\hline \multirow[t]{3}{*}{$\begin{array}{l}\text { Green } \\
\text { Procurement }\end{array}$} & GPT1 & $\begin{array}{l}\text { Install software to make material sourcing } \\
\text { more environmentally friendly. }\end{array}$ \\
\hline & GPT2 & Buys recycled IT equipment. \\
\hline & GPT3 & $\begin{array}{l}\text { Makes preference to IT hardware suppliers } \\
\text { that have a Green track record. }\end{array}$ \\
\hline
\end{tabular}

\begin{tabular}{|c|c|c|}
\hline & GPT4 & $\begin{array}{l}\text { Gives weight to environmental } \\
\text { considerations in equipment procurement. }\end{array}$ \\
\hline & GPT5 & $\begin{array}{lll}\begin{array}{l}\text { Deploy environment-friendly } \\
\text { procurement policy in our data center. }\end{array} & \text { IT } \\
\end{array}$ \\
\hline & GPT6 & $\begin{array}{l}\text { Purchase IT equipment from vendors that } \\
\text { offers take back option. }\end{array}$ \\
\hline \multirow[t]{6}{*}{$\begin{array}{l}\text { Green } \\
\text { Operation }\end{array}$} & GON1 & $\begin{array}{l}\text { Environmental consideration in planning IT } \\
\text { usage and operations in our data center. }\end{array}$ \\
\hline & GON2 & $\begin{array}{l}\text { Applied power management features of IT } \\
\text { equipment regularly used in our data center. }\end{array}$ \\
\hline & GON3 & $\begin{array}{l}\text { Turn off associated data center system when } \\
\text { not in use to saves energy. }\end{array}$ \\
\hline & GON4 & $\begin{array}{l}\text { Print data center report on both side of a } \\
\text { paper to reduce paper wastage. }\end{array}$ \\
\hline & GON5 & $\begin{array}{l}\text { Utilizes equipment that can monitor } \\
\text { workloads and to shut down when unused. }\end{array}$ \\
\hline & GON6 & $\begin{array}{l}\text { Uses free cooling in data centers to reduce } \\
\text { incurred energy cost. }\end{array}$ \\
\hline \multirow[t]{5}{*}{$\begin{array}{l}\text { Green } \\
\text { Disposal }\end{array}$} & GDL1 & $\begin{array}{l}\text { Recycle consumable equipment (e.g. } \\
\text { batteries, ink cartridges, and paper). }\end{array}$ \\
\hline & GDL2 & $\begin{array}{l}\begin{array}{l}\text { Disposes of IT equipment } \\
\text { environmentally friendly manner. }\end{array} \\
\end{array}$ \\
\hline & GDL3 & $\begin{array}{l}\text { Carryout policy on managing electronic } \\
\text { waste. }\end{array}$ \\
\hline & GDL4 & Reuse IT equipment. \\
\hline & GDL5 & $\begin{array}{l}\text { Refurbish old, outdated and obsolete IT } \\
\text { equipment. }\end{array}$ \\
\hline
\end{tabular}

Table 1 show the life cycle strategies and metrics used to verify each life cycle, where "Green design" "Green procurement" and "Green operation" are all measured with 6 different metrics with a 5 point Likert scale ranging from not applied as " 1 " and fully applied as " 5 ". "Green production" is measured with 8 different items; with a 5 point Likert scale ranging from not applied as "1" and fully applied as "5". Lastly "Green disposal" is measured with 5 different items; with a 5 point Likert scale ranging from not applied as " 1 " and fully applied as "5".

\subsection{Data collection}

Data was collected using questionnaire used to verify life cycle strategies, related to Green computing practice application in IT based industries data centers. Before administering the questionnaire to randomly and purposively selected respondents, 3 domain experts in Green computing area assessed the validity of the questionnaire items which lead to the refinement of a few questionnaire metrics or questions based on the feedback from the experts. In this study the reliability was measured using Cronbach's alpha which measure the internal consistency of a test and it is defined as number ranging from 0-9 [11]. Where the value of alpha is given as 0.986 as obtained from SPSS version 22 . After which link to the questionnaire survey was sent to the official email of IT practitioners, IT staffs in IT based industries in Malaysia, the email addresses were gotten from their organizations website. The respondents were more than 700 randomly and purposively sampled from IT based industries in Malaysia.

\subsection{Data analysis using descriptive statistics}

The results were based on survey questionnaire from different IT based industries that possess data center. After sending the survey questionnaire link, data was 
collected from 133 IT staffs responsible for performing technical and operational functionalities at their respective organizations data centers. The collected data helped to verify whether the lifecycle process presented in this research is feasible to be practically applicable with ease for data centers Greening or not.

Test was carried out to ascertain if all the life cycle strategies; Green design, Green production, Green procurement, Green operation and Green disposal fulfils the desired dimensions of sustainability (social, economic and environmental) and also provides recommendation as best practices on how IT based industries can address energy efficiency related issues, cost saving decrease, eco-friendly waste management, natural resource conservation and ensure that there is a limited amount of $\mathrm{CO}_{2}$ emission in the atmosphere.

Lastly the collected data also helps to find out if the life cycle strategies presented in this study provides operational solutions in assisting IT based industries data centers to apply more Greener practice.

\subsection{Results and findings}

The instrument used for data collection was developed into two main sections. Section A collects data regarding respondents' demographic information, whereas section B contained 5 life cycle strategies with associated metrics that measured life cycle strategies. The metrics were derived from review of literature on Greening data center and Green computing practice application. The data were analysed using descriptive statistics, responses to the five life cycle strategies measuring Green computing practice application in IT based industries data centers was analysed and presented as frequency in percentage, mean, standard deviation (SD), maximum $(\max )$, minimum $(\mathrm{min})$ and median value.

Table 2. Characteristic of the questionnaire respondents

\begin{tabular}{|c|c|c|}
\hline $\begin{array}{c}\text { Demographic } \\
\text { Profile }\end{array}$ & Options & Response \\
\hline \multirow{3}{*}{ Gender } & Male & $55.0 \%$ \\
\hline \multirow{3}{*}{ Age } & Female & $45.0 \%$ \\
\cline { 2 - 3 } & $<25$ & $1.01 \%$ \\
\cline { 2 - 3 } & $25-34$ & $41.43 \%$ \\
\cline { 2 - 3 } & $35-44$ & $43.43 \%$ \\
\cline { 2 - 3 } & $45-55$ & $13.13 \%$ \\
\hline \multirow{4}{*}{ Education } & $>55$ & $1.01 \%$ \\
\cline { 2 - 3 } & High School & $3.00 \%$ \\
\cline { 2 - 3 } & Diploma & $26.0 \%$ \\
\cline { 2 - 3 } & Bachelor's Degree & $35.0 \%$ \\
\cline { 2 - 3 } & Master's Degree & $23.0 \%$ \\
\hline Industry Country & PhD & $13.0 \%$ \\
\cline { 2 - 3 } & Malaysia & $0.00 \%$ \\
\cline { 2 - 3 } & \multicolumn{2}{|c}{ Others } \\
\hline
\end{tabular}

\begin{tabular}{|c|c|c|}
\hline \multirow[t]{10}{*}{ Industry Sector } & ICT, Communication and Media & $38.00 \%$ \\
\hline & Education and Research & $52.00 \%$ \\
\hline & Health and Community Services & $0.00 \%$ \\
\hline & Engineering and Construction & $2.00 \%$ \\
\hline & Finance, Banking and Insurance & $0.00 \%$ \\
\hline & $\begin{array}{l}\text { Government, Administration and } \\
\text { Defence }\end{array}$ & $6.00 \%$ \\
\hline & Manufacturing & $0.00 \%$ \\
\hline & Business, Wholesale and Retail & $0.00 \%$ \\
\hline & Personal, Professional & $2.00 \%$ \\
\hline & Others Services & $0.00 \%$ \\
\hline \multirow[t]{8}{*}{ Job Title } & $\begin{array}{c}\text { Business and Systems Analysts and } \\
\text { Programmers }\end{array}$ & $24.42 \%$ \\
\hline & ICT Managers & $18.60 \%$ \\
\hline & $\begin{array}{c}\text { ICT Network and Support } \\
\text { Professionals }\end{array}$ & $13.95 \%$ \\
\hline & Non ICT Specialist Managers & $2.33 \%$ \\
\hline & $\begin{array}{c}\text { Chief Executives, General Managers } \\
\text { and Legislators }\end{array}$ & $0.00 \%$ \\
\hline & Tertiary Education Lecturers & $12.79 \%$ \\
\hline & $\begin{array}{c}\text { Database Systems Administrators, } \\
\text { and ICT Security Specialists }\end{array}$ & $6.98 \%$ \\
\hline & Others & $20.93 \%$ \\
\hline \multirow{5}{*}{$\begin{array}{l}\text { Working } \\
\text { Experience }\end{array}$} & $0-5$ & $29.07 \%$ \\
\hline & $6-10$ & $25.58 \%$ \\
\hline & $11-15$ & $24.42 \%$ \\
\hline & $16-20$ & $12.79 \%$ \\
\hline & $>20$ & $8.14 \%$ \\
\hline \multirow[t]{4}{*}{ Industry Size } & Below 50 employees & $12.79 \%$ \\
\hline & 51-250 employees & $23.26 \%$ \\
\hline & 251- 1000 employees & $11.63 \%$ \\
\hline & Above 1000 employees & $52.33 \%$ \\
\hline \multirow{5}{*}{$\begin{array}{l}\text { Industry Founded } \\
\text { Date }\end{array}$} & Before 1967 & $5.81 \%$ \\
\hline & Between 1967-1980 & $18.60 \%$ \\
\hline & Between 1991-2000 & $34.88 \%$ \\
\hline & Between 2001-2010 & $33.72 \%$ \\
\hline & From 2011- Till date & $6.98 \%$ \\
\hline \multirow{6}{*}{$\begin{array}{l}\text { Industry Annual } \\
\text { Revenue }\end{array}$} & RM 90,000 or below & $19.75 \%$ \\
\hline & RM 90,000 to RM 900,000 & $14.81 \%$ \\
\hline & RM 900,000 to RM $2,700,000$ & $14.81 \%$ \\
\hline & RM $2,700,000$ to RM $4,500,000$ & $13.58 \%$ \\
\hline & RM 4, 500,000 to RM 9, 000,000 & $4.94 \%$ \\
\hline & RM $9,000,000$ or above & $32.10 \%$ \\
\hline
\end{tabular}

Table 2 shows the demographic characteristic of the questionnaire respondents in relation to individual and industries characteristics.

\subsubsection{Descriptive statistics}

In regards to the life cycle strategies and metrics presented in Table 1, findings for the verification of each life cycle strategy are presented below. The frequency response is represented as percentage distribution and descriptive statistics for Green design is shown in Table 3, where the metrics includes GDN1-GDN6.

Table 3. Descriptive statistic results for Green design metrics

\begin{tabular}{|c|c|c|c|c|c|c|c|c|c|c|c|}
\hline $\begin{array}{c}\text { Life } \\
\text { Cycle }\end{array}$ & Items & $\begin{array}{c}\mathbf{1} \\
\text { Not Applied }\end{array}$ & $\begin{array}{c}\mathbf{2} \\
\text { Partly Applied }\end{array}$ & $\begin{array}{c}\mathbf{3} \\
\text { Neutral }\end{array}$ & $\begin{array}{c}\mathbf{4} \\
\text { Applied }\end{array}$ & $\begin{array}{c}\mathbf{5} \\
\text { Fully Applied }\end{array}$ & Mean & SD & Min & Max & Median \\
\hline \multirow{3}{*}{$\begin{array}{c}\text { Green } \\
\text { Design }\end{array}$} & GDN1 & $3.23 \%$ & $4.84 \%$ & $17.74 \%$ & $51.61 \%$ & $22.58 \%$ & 3.85 & 0.93 & 1.00 & 5.00 & 4.00 \\
\cline { 2 - 11 } & GDN2 & $6.35 \%$ & $4.76 \%$ & $20.63 \%$ & $42.86 \%$ & $24.40 \%$ & 3.76 & 1.08 & 1.00 & 5.00 & 4.00 \\
\cline { 2 - 11 } & GDN3 & $3.17 \%$ & $4.76 \%$ & $23.81 \%$ & $42.86 \%$ & $25.40 \%$ & 3.83 & 0.97 & 1.00 & 5.00 & 4.00 \\
\cline { 2 - 11 } & GDN4 & $17.46 \%$ & $11.11 \%$ & $20.63 \%$ & $34.92 \%$ & $15.87 \%$ & 3.21 & 1.32 & 1.00 & 5.00 & 4.00 \\
\cline { 2 - 11 } & GDN5 & $15.87 \%$ & $12.70 \%$ & $20.63 \%$ & $36.51 \%$ & $14.29 \%$ & 3.21 & 1.29 & 1.00 & 5.00 & 4.00 \\
\cline { 2 - 11 } & GDN6 & $11.11 \%$ & $11.11 \%$ & $23.81 \%$ & $33.33 \%$ & $20.63 \%$ & 3.41 & 1.24 & 1.00 & 5.00 & 4.00 \\
\hline
\end{tabular}


Table 3 shows the findings for Green design metrics items GDN1 to GDN6. It can be seen that all metrics are fully applied. Finding further revealed that GDN1, GDN2 and GDN3 response frequency is higher than the other metrics in terms of application. In relation to the mean value as seen in Table 3 each of the have a mean value greater than 2.5 which is the least required mean value on a scale of 5. Table 3 also shows that the standard deviation value is lower for GDN1 and GDN3. This shows that the responses are quite similar in options selected in relation to Green design application in their data centers. Percentage distribution and descriptive statistics for Green production is shown in Table 4, where the metrics includes GPN1-GPN8.

Table 4. Descriptive statistic results for Green production metrics

\begin{tabular}{|c|c|c|c|c|c|c|c|c|c|c|c|}
\hline Life Cycle & Items & $\begin{array}{c}1 \\
\text { Not Applied }\end{array}$ & $\begin{array}{c}2 \\
\text { Partly Applied }\end{array}$ & $\begin{array}{c}3 \\
\text { Neutral }\end{array}$ & $\begin{array}{c}4 \\
\text { Applied }\end{array}$ & $\begin{array}{c}5 \\
\text { Fully Applied }\end{array}$ & Mean & SD & Min & Max & Median \\
\hline \multirow{8}{*}{$\begin{array}{c}\text { Green } \\
\text { Production }\end{array}$} & GPN1 & $14.06 \%$ & $10.94 \%$ & $14.06 \%$ & $46.88 \%$ & $14.06 \%$ & 3.36 & 1.25 & 1.00 & 5.00 & 4.00 \\
\hline & GPN2 & $15.63 \%$ & $9.38 \%$ & $26.56 \%$ & $29.69 \%$ & $18.75 \%$ & 3.27 & 1.30 & 1.00 & 5.00 & 3.00 \\
\hline & GPN3 & $23.44 \%$ & $9.38 \%$ & $10.94 \%$ & $40.63 \%$ & $15.63 \%$ & 3.16 & 1.43 & 1.00 & 5.00 & 4.00 \\
\hline & GPN4 & $17.19 \%$ & $9.38 \%$ & $17.19 \%$ & $40.63 \%$ & $15.63 \%$ & 3.28 & 1.32 & 1.00 & 5.00 & 4.00 \\
\hline & GPN5 & $9.52 \%$ & $9.52 \%$ & $17.46 \%$ & $41.27 \%$ & $22.22 \%$ & 3.57 & 1.20 & 1.00 & 5.00 & 4.00 \\
\hline & GPN6 & $10.94 \%$ & $7.81 \%$ & $20.31 \%$ & $34.38 \%$ & $26.56 \%$ & 3.58 & 1.26 & 1.00 & 5.00 & 4.00 \\
\hline & GPN7 & $14.06 \%$ & $9.38 \%$ & $25.00 \%$ & $26.56 \%$ & $25.00 \%$ & 3.39 & 1.33 & 1.00 & 5.00 & 4.00 \\
\hline & GPN8 & $12.50 \%$ & $15.63 \%$ & $15.63 \%$ & $32.81 \%$ & $23.44 \%$ & 3.39 & 1.33 & 1.00 & 5.00 & 4.00 \\
\hline
\end{tabular}

Table 4 shows the findings for Green production metrics GPN1 to GPN8. The results shows that GPN1, GPN3 and GPN4 all have higher relevance priority and are applied in relation to Green production in data centers, although GPN6 and GPN8 are averagely applied, whereas values from GPN2 and GPN7 are perceived by the respondents to neutrally being applied. For the mean all items possess mean value greater than
2.5, with GPN7 and GPN8 having the highest mean of 3.39. in regards to the standard deviation values all metrics values deviates a bit further from "1" meaning that the response from the respondents are further apart from each other. Percentage distribution and descriptive statistics for Green procurement is shown in Table 5, where the metrics includes GPT1-GPT6.

Table 5. Descriptive statistic results for Green procurement metrics

\begin{tabular}{|c|c|c|c|c|c|c|c|c|c|c|c|}
\hline $\begin{array}{c}\text { Life } \\
\text { Cycle }\end{array}$ & Items & $\begin{array}{c}\mathbf{1} \\
\text { Not Applied }\end{array}$ & $\begin{array}{c}\mathbf{2} \\
\text { Partly Applied }\end{array}$ & $\begin{array}{c}\mathbf{3} \\
\text { Neutral }\end{array}$ & $\begin{array}{c}\mathbf{4} \\
\text { Applied }\end{array}$ & $\begin{array}{c}\mathbf{5} \\
\text { Fully Applied }\end{array}$ & Mean & SD & Min & Max & Median \\
\hline \multirow{2}{*}{$\begin{array}{c}\text { Green } \\
\text { Procure- } \\
\text { ment }\end{array}$} & GPT1 & $18.75 \%$ & $10.94 \%$ & $12.50 \%$ & $37.50 \%$ & $20.31 \%$ & 3.30 & 1.40 & 1.00 & 5.00 & 4.00 \\
\cline { 2 - 11 } & GPT2 & $25.00 \%$ & $17.19 \%$ & $17.19 \%$ & $21.88 \%$ & $18.75 \%$ & 2.92 & 1.46 & 1.00 & 5.00 & 3.00 \\
\cline { 2 - 11 } & GPT3 & $18.75 \%$ & $17.19 \%$ & $20.31 \%$ & $29.69 \%$ & $14.06 \%$ & 3.03 & 1.33 & 1.00 & 5.00 & 3.00 \\
\cline { 2 - 11 } & GPT4 & $12.50 \%$ & $17.19 \%$ & $17.19 \%$ & $29.69 \%$ & $23.44 \%$ & 3.34 & 1.34 & 1.00 & 5.00 & 4.00 \\
\cline { 2 - 11 } & GPT5 & $12.70 \%$ & $17.46 \%$ & $15.87 \%$ & $34.93 \%$ & $19.05 \%$ & 3.30 & 1.30 & 1.00 & 5.00 & 4.00 \\
\cline { 2 - 11 } & GPT6 & $14.29 \%$ & $12.70 \%$ & $22.22 \%$ & $38.10 \%$ & $12.70 \%$ & 3.22 & 1.24 & 1.00 & 5.00 & 4.00 \\
\hline
\end{tabular}

Table 5 shows the findings for Green procurement metrics GPT1 to GPT1. The results show that all metrics were applied in the respondents data centers except from GPT2 which measure if the respondents organizations "Buys recycled IT equipment for data center use". The percentage was low for this metrics showing that IT based industries do not buy recycled equipment to be deployed and used in their data centers. In regards to the mean, all values where greater than 3.5, MF2 mean value is also given as 2.92 which is still greater than the required 2.5 threshold value. The standard deviation values of each metrics were also greater that " 1 " showing the response from the respondents are partly spatially deviated in terms of the respondents perception toward Green procurement application in their organizations data centers. Percentage distribution and descriptive statistics for Green operation is shown in Table 6, where the metrics includes GON1-GON6.

Table 6. Descriptive statistic results for Green operation metrics

\begin{tabular}{|c|c|c|c|c|c|c|c|c|c|c|c|}
\hline $\begin{array}{c}\text { Life } \\
\text { Cycle }\end{array}$ & Items & $\begin{array}{c}1 \\
\text { Not Applied }\end{array}$ & $\begin{array}{c}2 \\
\text { Partly Applied }\end{array}$ & $\begin{array}{c}3 \\
\text { Neutral }\end{array}$ & $\begin{array}{c}4 \\
\text { Applied }\end{array}$ & $\begin{array}{c}5 \\
\text { Fully Applied }\end{array}$ & Mean & SD & Min & Max & Median \\
\hline \multirow{6}{*}{$\begin{array}{c}\text { Green } \\
\text { Operatio } \\
n\end{array}$} & GON1 & $8.20 \%$ & $9.84 \%$ & $26.23 \%$ & $42.62 \%$ & $13.11 \%$ & 3.43 & 1.09 & 1.00 & 5.00 & 4.00 \\
\hline & GON2 & $6.56 \%$ & $13.11 \%$ & $21.31 \%$ & $39.34 \%$ & $19.67 \%$ & 3.52 & 1.14 & 1.00 & 5.00 & 4.00 \\
\hline & GON3 & $3.28 \%$ & $6.56 \%$ & $14.75 \%$ & $39.34 \%$ & $36.07 \%$ & 3.98 & 1.03 & 1.00 & 5.00 & 4.00 \\
\hline & GON4 & $3.28 \%$ & $2.28 \%$ & $8.20 \%$ & $44.26 \%$ & $40.98 \%$ & 4.16 & 0.94 & 1.00 & 5.00 & 4.00 \\
\hline & GON5 & $16.39 \%$ & $6.56 \%$ & $3.11 \%$ & $40.98 \%$ & $22.95 \%$ & 3.48 & 1.35 & 1.00 & 5.00 & 4.00 \\
\hline & GON6 & $16.39 \%$ & $8.20 \%$ & $21.31 \%$ & $37.70 \%$ & $16.39 \%$ & 3.30 & 1.30 & 1.00 & 5.00 & 4.00 \\
\hline
\end{tabular}

Table 6 shows the findings for Green operation metrics GON1 to GON6. The results show that all metrics are applied in their industry for Green operation strategy based on the fact that more than $37.70 \%$ respondents as seen from GON6 metrics to $44.26 \%$ GON4 metrics agreed that they apply Green operation 
strategies in their industry data center. The mean were all above 3.00 values, with GON4 possessing a mean of 4.16 outlining that in the respondents individual data centers they print data center reports on both side of a paper to reduce paper wastage thus saving the environment. For the standard deviation values each metric are between 0.94 for GON4 which is very good value based on the value nearness to " 1 " and the highest standard deviation value is 1.35 for GON5 which is still acceptable. Table 7 shows the findings for Green disposal metrics GDL1 to GDL5. The results show that all metrics are applied in IT based industries data center based on the percentage values on the all the metrics which range from GDL4 as $45.90 \%$ to GDL5 which possesses a value of $35.00 \%$. The mean are all above 3.50 and the standard deviation of the five metrics are almost similar ranging from 1.05 for GDL2 to 1.34 for GDL3 Percentage distribution and descriptive statistics for Green disposal is shown in Table 7, where the metrics includes GDL1-GDL5.

Table 7. Descriptive statistic results for Green disposal metrics

\begin{tabular}{|c|c|c|c|c|c|c|c|c|c|c|c|}
\hline $\begin{array}{c}\text { Life } \\
\text { Cycle }\end{array}$ & Items & $\begin{array}{c}1 \\
\text { Not Applied }\end{array}$ & $\begin{array}{c}2 \\
\text { Partly Applied }\end{array}$ & $\begin{array}{c}3 \\
\text { Neutral }\end{array}$ & $\begin{array}{c}4 \\
\text { Applied }\end{array}$ & $\begin{array}{c}5 \\
\text { Fully Applied }\end{array}$ & Mean & SD & Min & Max & Median \\
\hline \multirow{5}{*}{$\begin{array}{c}\text { Green } \\
\text { Disposal }\end{array}$} & GDL1 & $6.56 \%$ & $8.20 \%$ & $16.39 \%$ & $44.26 \%$ & $24.59 \%$ & 3.72 & 1.12 & 1.00 & 5.00 & 4.00 \\
\hline & GDL2 & $4.92 \%$ & $6.56 \%$ & $18.03 \%$ & $44.26 \%$ & $26.23 \%$ & 3.80 & 1.05 & 1.00 & 5.00 & 4.00 \\
\hline & GDL3 & $13.33 \%$ & $11.67 \%$ & $13.33 \%$ & $36.67 \%$ & $25.00 \%$ & 3.48 & 1.34 & 1.00 & 5.00 & 4.00 \\
\hline & GDL4 & $8.20 \%$ & $6.56 \%$ & $16.39 \%$ & $45.90 \%$ & $22.95 \%$ & 3.69 & 1.14 & 1.00 & 5.00 & 4.00 \\
\hline & GDL5 & $11.67 \%$ & $13.33 \%$ & $16.67 \%$ & $35.00 \%$ & $23.33 \%$ & 3.45 & 1.30 & 1.00 & 5.00 & 4.00 \\
\hline
\end{tabular}

\section{Discussion}

This research study aims to facilitate the Greening of data centers in IT based industries by applying Green computing practices. In the course of this paper 5 different life cycle strategies were derived from literature review as were verified based on associated metrics or item from questionnaire data. Results from this study shows that all the 5 life cycle strategies to be applied for Green computing practice in IT based industries data centers are important and should be considered by data centers administrators, IT practitioners and staffs in IT based industries data centers. Moreover no new life cycle strategy was discovered from the data collected from the questionnaire session.

Finding from this study shows the Green design practice should be applied in IT based industries data center, this finding is consistent with research carried out by Reza et al. [12] where the researcher encourages the application deployment of ecologically sound servers, cooling equipment and computer components such as LED monitor in data centers. Findings from this study regarding Green production is similar with previous study carried out by Pichetpongsa and Campeanu [13] where the author suggested the installing and usage of electronic components, computers and other related subsystems in data centers that possesses low or no effect on the natural environment.

Furthermore findings regarding Green procurement support OGCIS [10] guideline where Green procurement is considered as one of the life cycle phase from Green ICT practice implementation. Our findings also corroborates with case study findings presented by Anthony and Majid [16]; Huang [17] where the authors mentioned that IT industries adheres to sourcing policy and Green purchasing guidelines when purchasing IT facilities and equipment. The findings are regarding Green operation is similar to results presented by Molla [15] in their research where the authors mentioned that
IT based industries should deploy power performance management of data centers facilities to decreasing energy utilization thereby decreasing $\mathrm{CO} 2$ emissions from data centers. Additionally the results on Green disposal suggests this life cycle strategy is most adopted Green computing practice applied in IT based industries this is in line with finding presented by Huang [17] in his research on ecological sustainable IS development where the author mentioned that most organization only practice recycling reuse and refurbishing of IT infrastructure as Green computing practice in their industrial operations.

\section{Practical and research implication}

The practical implication of this study correlates to the life cycle strategies which comprises of Green design, Green production, Green procurement, Green operation and Green disposal that provides an approach to describe how data center managers, IT practitioners and staffs can apply Green computing solutions in their new or existing data centers to make them emits less $\mathrm{CO}$ 2, energy efficient and thereby reducing cost incurred. The Green computing life cycle strategies can enhance the efficiency of data center based on 5 steps to be applied to properly deploy IT based industries data centers alongside metrics that can be utilized by data centers administrators, IT practitioner and staffs to measure the sustainability of data center in terms of energy efficiency, cost saving, natural resource preservation, waste management, and $\mathrm{CO}_{2}$ emissions.

The research implication of this study is associated to the Green computing life cycle strategies and associated Green metrics which can be utilized as a benchmark by data center managers in IT based industries to apply Green practice initiatives in their data center to make the data centers more eco-friendly. The life cycle strategies does not only offer understanding of diverse aspects of Green computing, but can also be used as a guideline tool to assess the activities needed to apply Green computing initiatives into action. As a continuing 
evaluation tool, the life cycle strategies acts both as a strategic Green computing practice application bridge and as an interim reference manual for policy-making and strategic decision making regarding data centers deployment for enterprise gain.

\section{Conclusion, limitation and future work}

This research study describes Green computing practice application towards supporting IT based industries data center in regards to cost saving decrease, energy efficiency, eco-friendly waste management, natural resource conservation and $\mathrm{CO}_{2}$ emission reduction towards sustainability attainment. The presented life cycle strategies also contains individual metrics to categorize data center practice into measureable units contingent on measuring the routine of data center in terms of cost saving decrease, energy efficiency, eco-friendly waste management, natural resource conservation and $\mathrm{CO} 2$ emission reduction.

In this descriptive study secondary data was collected from existing literatures on data center Greening and Green computing, after which the life cycle strategies which comprises of Green design, Green production, Green procurement, Green operation and Green disposal was derived. Primary data was collected based on a questionnaire from more than 133 respondents in IT based industries to verify each of the derived life cycle strategies based on individual metrics. Finding from the analysed questionnaire data shows that all the life cycle strategies are significant and should be considered by IT based industries in Greening their data centers sustainability attainment.

The approach presented in this study provides a formative guide, which could simplify be reflected and applied by novice IT practitioners and staffs who are new to benchmarking and Greening data centers. This study thus provides an effective and clear approach of presenting the general Green computing practice application concept. Hence in summary findings from this study presents a realistic, practical and uncomplicated life cycle strategies, which can easily be deployed in real working environment. The life cycle strategies are feasible for total data center performance and management also meets industry standards for data centers by diminishing overall cost of ownership and lastly provides a simple method for integrating benchmarking, measuring concepts towards data centers Greening. The limitation of this study is related to the data collection which involves only respondents in IT based industries in Malaysia. Hence finding from this study cannot be generalized to other countries. In future work data will be collected from other countries and other domain to verify if the results will be same or different and if any new life cycle strategies will emerge in the cause of data collection.

\section{References}

1. S. Karanasios, V. Cooper, H. Deng, A. Molla, S. Pittayachawan, Antecedents to greening data centres: A conceptual framework and exploratory case study (2010).

2. S. L. Hart, Beyond Greening: Strategies for a Sustainable World. Harvard Bus. Rev. 75, 1, 66-76 (1997).

3. M. Uddin, M. Talha, A. A. Rahman, A. Shah, J. A. Khader, J. Memon, Green Information Technology (IT) framework for energy efficient data centers using virtualization. International Journal of Physical Sciences, 7, 13, 2052-2065 (2012).

4. S. Murugesan, Going Green with IT: Your Responsibility toward Environmental Sustainability. Cutter Business-IT Strategies Executive Report, 10, 8, 1-25 (2007).

5. A. J. Bokolo, C. P. Noraini, A Framework for Adoption and Implementation of Green IT/IS Practice in IT Governance. Proceedings of Third International Conference on Green Computing, Technology and Innovation (ICGCTI2015), SDIWC, Serdang Malaysia, 38-48 (2015).

6. M. J. Pawlish, A. S. Varde, A decision support system for green data centers. Proceedings of the $3 r d$ workshop on Ph. D. students in information and knowledge management, 47-56 (2010).

7. R. R. Schmidt, E.E. Cruz, M. K. Iyengar, Challenges of Data Center Thermal Management. IBM Journal, 49, 4/5, 709-723 (2005).

8. G. Schulz, The Green and Virtual Data Center. FL: CRC Press, Taylor \& Francis (2009).

9. A. Molla, V. Cooper, Greening data centres: The motivation, expectancy and ability drivers (2014).

10. ogcio.gov.hk, green data centre practice (2013).

11. J. F. Hair, W.C. Black, B.J. Babin, R.E. Anderson, R.L. Tatham, Multivariate Data Analysis, 6th edn, Pearson Prentice Hall, Upper Saddle River, N.J (2006).

12. K. Raza, V. K. Patle, S. Arya, A review on green computing for eco-friendly and sustainable it. Journal of Computational Intelligence and Electronic Systems, 1, 3-16 (2012).

13. N. Pichetpongsa, G. Campeanu. Analysis of Green Information Technology in Dell and Toshiba Companies. IDT: Malardalen University (2012).

14. B. Saha, Green computing. International Journal of Computer Trends and Technology (IJCTT), 14, 2, 46-50 (2014).

15. A. Molla, The reach and richness of green IT: a principal component analysis. Australian Conference on Information Systems, 754-764 (2009).

16. B. J. Anthony, M. A. Majid, Development of a Green ICT Model for Sustainable Enterprise Strategy. Journal of Soft Computing and Decision Support Systems, 3, 3, 1-12 (2016).

17. A. H. Huang, A model for environmentally sustainable information systems development. Journal of Computer Information Systems, 49, 4, 114-12 (2009).

18. Environmental Protection Agency (EPA), Report to Congress on Server and Data Center Energy Efficiency - Public Law 109-431, Environmental Protection Agency, Washington, DC (2007). 